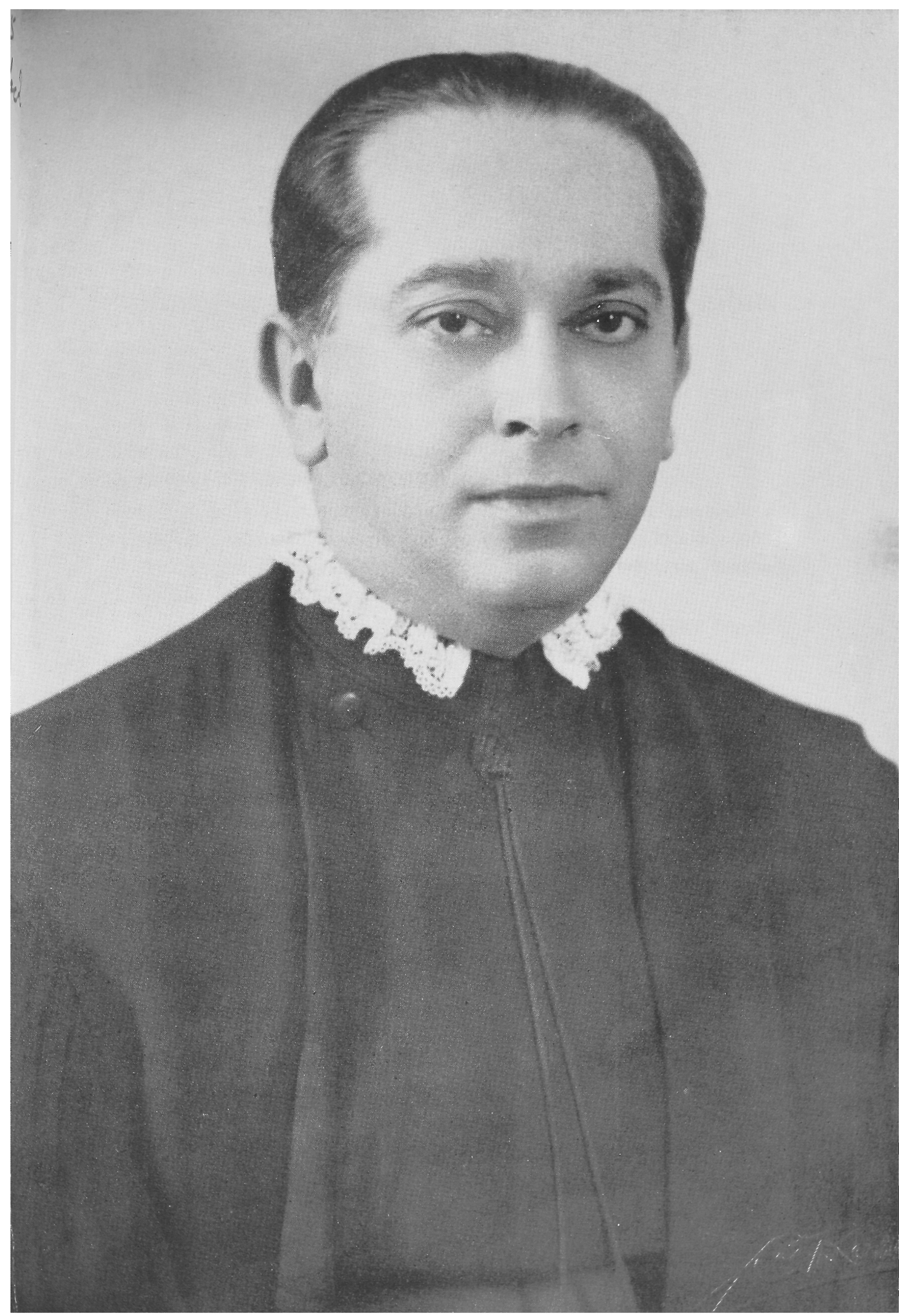


PROF. TEOTONNIO MONTEIRO DE BARROS FILHO. 


\section{Professor Theotônio Monteiro de Barros Filho.}

O professor Theotônio Monteiro de Barros Filho nasceu a 31 de agôsto de 1901, na cidade de Ribeirão Preto. Foran seus pais o Sr. Theotônio Monteiro de Barros e D. Judith Soares Monteiro de Barros.

Fêz os estudos primários no Colégio Moura Lacerda e no Externato Francisco Leite e os secundários, no Ginásio do Estado de Ribeirão Preto, tendo sido o orador da turma de bacharés em Ciências e Letras de 1917.

Matriculou-se na Faculdade de Direito de São Paulo em 1919 concluindo o curso jurídico em 1923. Demonstrando desde muito jovem seus dons oratórios foi escolhido orador da chave, em sua turma. Aluno distinto em tôdas as cadeiras do curso, participou também dos movimentos cívicos do Centro Acadêmico XI de Agôsto. Fazendo parte da Liga Nacionalista durante quatro anos, percorreu como seu delegado diversos municípios do interior, defendendo em campanhas o voto secreto e o serviço militar.

Em 1932 quando da Revolução Constitucionalista, servindo no $3 .^{\circ}$ Batalhão do Regimento 9 de Julho lutou em Eleutério, Itapira, Morro Gravi, Mogi Mirim e Cosmópolis; ascendeu até o posto de capitão após ter sido promovido a 2. Tenente no "front".

Foi a seguir um dos fundadores da Federação dos Voluntários de São Paulo, fazendo parte do seu dirretório central.

Aos 33 anos eleito deputado federal à Constituinte Brasileira de 1934, integrou a bancada paulista da "Chapa Única por São Paulo Unido". Participando ativamente dos tra- 
balhos da Bancada Paulista combateu, em memorável discurso, a pena de morte que se pretendia implantar no sistema brasileiro de repressão à criminalidade; iniciando campanha de repercussão nacional na imprensa, pela limitação de certas correntes imigratórias, apresentou judicioso estudo que fundamentou a emenda sôbre o assunto, resultando a limitação fixada pela Carta de 1934 e mantida na de 1937. Reeleito deputado Federal para a 1. ${ }^{a}$ Legislatura Ordinária, pelo partido Constitucionalista, foi investido no cargo de sub-lider de sua bancada, no qual permaneceu até novembro de 1937, quando dissolvida a Câmara.

Reiniciou então seus trabalhos profissionais e logo em seguida, em 1938, candidatou-se à cátedra de Legislação Social da Faculdade de Direito de São Paulo, defendendo a tese Justiça do Trabalho, que lhe outorgou o grau de doutor em Ciências Jurídicas e Sociais e a livre docência da matéria.

Na interventoria do Dr. Fernando Costa em São Paulo, em 1941, exerceu o cargo de Diretor do Departamento do Serviço Social do Estado, ficando marcada indelèvelmente sua atuação nesse setor. Nesse mesmo ano, com a tese As Taxas e os Seus Principais Problemas Teóricos, conquistou brilhantemente a cátedra de Ciências das Finanças, da qual tomou posse a 25 de novembro.

Suas atividades anteriores, comprovadamente inteligentes e inovadoras levaram-no, em 1942, à Secretaria da Educação e Saúde; em 1943 à Secretaria da Segurança Pública; em 1946, como delegado do Brasil, à Conferência de Comércio e Emprêgo da onv, em Londres; em 1947 em Genebra e em 1948 em Havana.

Novamente eleito deputado Federal em 1954 exerceu o mandato até 1958; escolhido pelo Govêrno Federal ocupou o Ministério da Educação em janeiro de 1963, demitindo-se em junho daquele ano.

Pela relevância de suas funções, exercidas sempre com probidade e descortino em prol do desenvolvimento polí- 
tico, econômico e intelectual de sua terra, recebeu o Prof. Theotônio M. de B. Filho várias e altas condecorações do Brasil e do exterior: a de Grande Oficial da Ordem do Mérito, do Paraguai; Medalha do Mérito Tamandaré, Comenda da Ordem do Mérito Aeronáutico e de Grande Oficial da Ordem do Mérito Militar.

É membro da Ordem dos Advogados do Brasil; do Instituto da Ordem dos Advogados do Brasil; da Acadêmia de Ciências Econômicas do Instituto de Economia da Associação Comercial de São Paulo.

A par de suas atividades docentes, políticas, administrativas e advocatícias, publicou trabalhos de alto teor doutrinário, alguns dos quais relacionamos a seguir.

\section{Bibliografia do Professor Theotonio Monteiro de Barros Filho.}

Justiça do Trabalho. São Paulo, Revista dos Tribınais. 1938 -

As taxas e seus Principais Problemas Teóricos. São Paulo, Revista dos Tribunais, 1941 e no Digesto Econômico, n.o 109, 1953.

Estrutura Financeira do Brasil. (In Laufenburger, Henry. Finanças Comparadas. s.d., p. 379-411).

Balanço Econômico e Político de uma Época Histórica, in Revista da Faculdade de Direito, São Paulo, 1943-1944, v. 39, p. 209 a 227.

A História da Doutrina da Incidência, in-Revista da Faculdade de Direito de São Paulo, 1942, v. 38, p. 51-58.

O Imposto Sindical, in Revista Forense. Rio de Janeiro. 1951, a. 48, v. 134, p. 587-594 e no Digesto Econômico, n. 73, 1950.

O Prazo para o Registro de Contudores, in Projetos da Câmara dos Deputados Federais, Rio de Janeiro, 1937, v. 5. ${ }^{\circ}$.

As Américas e o Mundo; Conferência pronunciada, a 14 de abril, no Teatro Municipal, por ocasião da festa comemoraliva do Dia Panamericano, 1 volume, São Paulo, 1942.

Emenda ao Orçamento; é possível emendar o orçamento após encerrado o prazo constitucional de sua elaboraçâo legislativa? in Revista da Faculdade de Direito, São Paulo, 1948, v. XLIII, p. 146.

Impôsto de Indústrias e Profissões; imposto indireto; isenção fiscal; cooperativas (parecer), in Revista Forense. Rio de Janeiro. 1953, a. 50 , v. 148, p. $88-90$. 
Impôsto sôbre Combustíveis Líquidos ou gazosos: impôsto de indústrias e profissões; taxas de previdência social; a lei n.0 2975; (parecer). In Revista Forense. Rio de Janeiro 1957, a. 54, v. 171, p. 102-114.

Sôbre o Número de Inspetores nos Institutos Fiscalizados de Ensino Superior. (Parecer), in Projetos da Câmara dos Deputados Federais, Rio de Janeiro, 1935, v. 3.

Locação - Fropriedade agrícolo - Aluguel pago anualmente - Arrendatários que incorreram em mora por culpa do arrendador Malícia dêste - Ação de consignação proposta tempestivamente - Aplicação dos arts. 120 e 972 do Código Civil. (Parecer), in Revista dos Tribunais, São Paulo, 1945, v. 154, p. 11.

Moeda Nacional - Contrato de arrendamento que previra sua Interpretação da expressão "mudança da moeda corrente do país" Se, além da mutação legal do sistema monetário, abrange a transformação econômica do dinheiro. (Parecer), in Revista dos Tribunais, São Paulo.

Requisição de Bens e Serviços; tabelamento de preços, comissão federal de abastecimento e preços; (Parecer). In Revista Forense. Rio de Janeiro, 1953, a. 50, v. 150, p. 116-119.

Prof. Candido Motta, in Vinte Anos Depois... São Paulo, 1943, p. 57.

Pregos e o Problema do Momento, no Digesto Econômico, n. ${ }^{\circ}$ 9, agôsto de 1945.

Perspectivas do Comércio Internacional, no Digesto Econômico, n. ${ }^{\circ} 30$, maio de 1947.

O Programa de Recuperação Européia, no Digesto Econômico, n. ${ }^{\circ} 47$, outubro de 1948.

A Conferência de Araxá, no Digesto Econômico, n. ${ }^{\circ}$ 58, setembro de 1949.

Noções Gerais de, Finanças, no Digesto Econômico, n. ${ }^{\circ} 85$, dezembro de 1951.

Limitações Constitucionais ao Poder de Tributar, no Digesto Econômico, n. ${ }^{\circ} 88$, março de 1952.

Direito Orçamentário, no Digesto Econômico, n.o 100, março de 1953.

o Parlamentarismo e a Conjuntura Nacional, no Digesto Econômico, n. ${ }^{\circ} 129$, maio/junho de 1956.

Crédito Rural, no Digesto Econômico, n. ${ }^{\circ}$ 132, nov./dez. de 1956.

Aprovação dos Atos do Govêrno. (Discurso na Constituinte de 1934). Imprensa Oficial do Estado, São Paulo, 1935.

Constituição das Fôrças Armadas. (Discurso na Constituinte de 1934). Imprensa Oficial do Estado, São Paulo, 1935. 
Eleição direta do Presidente da República. (Discurso na Constituinte de 1934) - Imprensa Oficial do Estado, São Paulo, 1935.

Ensino Religioso. (Discurso na Constituinte de 1934) - Imprensa Oficial do Estado, São Paulo, 1935.

Imigração. (Discurso na Constituinte de 1934) - Imprensa Oficial do Estado, São Paulo, 1935.

Inelegibilidade do Chefe do Govêrno - (Discurso na Constituinte de 1934)) Imprensa Oficial do Estado, São Paulo, 1935.

Pena de Morte (Discurso na Constituinte de 1934) - Imprensa Oficial do Estado, São Paulo, 1935.

Responsabilidade do Chefe do Govêrno - (Discurso na Constituinte de 1934) Imprensa Oficial do Estado, São Paulo, 1935.

Mandado de Segurança em Defesa do Governador Muniz Falcão de Alagoas in Mandado de Segurança, edição da Casa de Rui Barbosa, Rio de Janeiro, 1960. 